\title{
Evaluation of MRP1-5 Gene Expression in Cystic Fibrosis Patients Homozygous for the $\Delta$ F508 Mutation
}

\author{
ILSE HURBAIN, ISABELLE SERMET-GAUDELUS, BENOIT VALLÉE, \\ MARIE-NOËLLE FEUILLET, GÉRARD LENOIR, JEAN-FRANÇOIS BERNAUDIN, \\ ALEKSANDER EDELMAN, AND ANNE FAJAC
}

Service d'Histologie-Biologie Tumorale, UPRES EA3499, Hôpital Tenon, 75020 Paris [I.H., J.-F.B., A.F.]; Inserm U467, Faculté Necker, 75015 Paris [I.S.-G., B.V., A.E.]; Service de Pédiatrie, Hôpital Necker, 75015 Paris [I.S.-G., G.L.]; Service de Biochimie, Hôpital Necker, 75015 Paris, France [M.-N.F.]

\begin{abstract}
Cystic fibrosis (CF), due to mutations of the cystic fibrosis transmembrane conductance regulator (CFTR), exhibits a wide range of disease severity, even among $\Delta$ F508 homozygous patients, and the mechanisms of this variability have yet to be elucidated. In view of the close structural homology and possible functional overlap between CFTR and Multidrug Resistanceassociated Proteins (MRPs), MRPs were investigated as potentially relevant factors in $\mathrm{CF}$ pathophysiology. MRP1-5 gene expression was analyzed in nasal respiratory epithelial cells from $\Delta$ F508 homozygous patients $(n=19)$ and control subjects $(n=$ 20) using semiquantitative RT-PCR. Significantly lower $M R P 1$ and MRP5 transcript levels were found in CF patients than in control subjects. $M R P 1$ and $M R P 5$ transcript levels were strongly correlated $(r=0.71)$. In CF patients, low MRP1 transcript levels were associated with more severe disease as assessed by the Shwachman score. A relation was also observed between MRP1 levels and presence of a cAMP-independent chloride conductive
\end{abstract}

\section{ABSTRACT}

pathway, as determined by a halide-sensitive fluorescent assay. These results suggest that MRPs, especially MRP1, might play a role in CF phenotype and might therefore constitute a target for a novel pharmacotherapy of CF. (Pediatr Res 54: 627-634, 2003)

CF, cystic fibrosis

\section{Abbreviations}

CFTR, cystic fibrosis transmembrane conductance regulator dNTP, deoxynucleoside triphosphate

FEV1, forced expiratory volume

FVC, forced vital capacity

MDR1, multidrug transporter 1

Pgp, P-glycoprotein

MRPs, multidrug resistance-associated proteins

RT-PCR, reverse transcription-PCR

SPQ, 6-methoxy-N-3-sulfopropylquinolinium
Cystic fibrosis (CF) is caused by mutations in the gene encoding the Cystic Fibrosis Transmembrane conductance Regulator (CFTR), a member of the ATP Binding Cassette (ABC) transporter superfamily. The well-established function of CFTR is to act as a cAMP-activated chloride channel. However, CFTR has many other roles, such as regulating epithelial transport proteins (1-3), vesicle trafficking (4) and acidification of intracellular organelles (5). CF, characterized by bronchopulmonary disease and pancreatic insufficiency,

Received January 14, 2003; accepted July 16, 2003.

Correspondence: Anne Fajac, M.D., Service d'Histologie-Biologie Tumorale, Hôpital Tenon, 4 rue de la Chine 75020 Paris, France; e-mail: anne.fajac@tnn.ap-hop-paris.fr

Supported by grants from "ABCF Protéines" Association, "Vaincre la Mucoviscidose" Association and by Université Paris VI.

DOI: 10.1203/01.PDR.0000090926.16166.3F presents a wide range of disease severity, especially in terms of lung disease, even among patients harboring the same mutation.

We have previously shown that the cAMP-dependent chloride channel function of CFTR might be relatively conserved in some patients with a $\Delta$ F508 homozygous deletion, which is the most frequent mutation among Caucasians (6). We have shown that this heterogeneity of CFTR function is linked to the clinical course of the disease. Therefore, certain factors may modulate or complement CFTR function in some CF patients. The factors responsible for this residual CFTR function have not yet been elucidated, but might be exogenous factors such as environmental factors, or endogenous factors such as so-called "modifier" genes. Whether this residual chloride channel function per se causes less severe disease or whether another 
residual nonchannel CFTR function may be more relevant in CF pathophysiology remains to be determined.

Multidrug Resistance-associated Proteins (MRPs), which form a family of at least nine recently identified membrane proteins, share the closest structural homology with CFTR, belonging to the same subfamily $\mathrm{C}$ of the $\mathrm{ABC}$ transporter superfamily (7-8). Some MRPs, especially MRP1 and MRP5, are expressed in most human tissues, while others, such as MRP2 and MRP3, have a more limited expression pattern mainly in liver and gut $(9-10)$. MRPs are characterized by their ability to export organic anions, either glutathione, glucuronate and sulfate conjugated molecules or unmodified substances, out of cells. Although the physiologic functions of these proteins are still under investigation, there is evidence to suggest that these proteins might be involved in drug resistance, detoxification, inflammation and oxidative stress (11-12).

In addition to the structural homology between CFTR and MRPs, there might be an overlap in functions between these proteins. The hypothesis that CFTR could be complemented by MRPs was driven from the case of a CF patient whose lung function improved after receiving anticancer drugs known to induce MRPs (13). In in vitro models, CFTR has been recently shown to efflux organic anions out of cells (14) and transport glutathione (15), which are known to be two main functional characteristics of MRPs.

In the present study, we therefore investigated MRPs gene expression and chloride conductive pathways in nasal respiratory epithelial cells from CF patients. We examined MRP1,$2,-3,-4$ and -5 transcript levels by semiquantitative RT-PCR in $\Delta$ F508 homozygous patients and control subjects. In CF patients, we also examined the relationship between MRPs gene expression and clinical status on one hand and the existence of a chloride conductive pathway, on the other, by using a halidesensitive SPQ (6-methoxy-N-3-sulfopropylquinolinium) fluorescent dye assay (6).

\section{METHODS}

\section{Subjects}

This study was carried out on healthy control subjects $(n=$ $20)$ and $\Delta$ F508 homozygous patients $(n=19)$. All CF patients ( 9 girls and 10 boys; mean age: $12 \mathrm{y}$, range: $5-30$ ) presented pancreatic insufficiency. Control subjects had a normal sweat test and had been negatively screened for the 30 most frequent CFTR mutations. Exclusion criteria were recent upper respiratory tract infection, smoking and nasal polyps.

Clinical status was assessed by measuring the forced expiratory volume (FEV1) and the forced vital capacity (FVC) to assess pulmonary function and by the Shwachman score (16) to assess overall disease severity. FEV1 and FVC were expressed as percentages of predicted values for age and sex. Shwachman score is based on four criteria, which are given equal weight, namely 25 points: the general activity, the findings on physical examination, the nutritional status and the findings on chest roentgenograms (maximum score is therefore 100).
This study was approved by our institutional review board. Before the study, written informed consent was obtained from the older children and from the guardian of each child.

\section{Cells}

Nasal respiratory epithelial cells (approximately $1 \times 10^{6}$ cells per subject) were obtained by gentle brushing of the middle turbinate. Brushes were immediately placed in cold Dulbecco's Modified Eagle's Medium (DMEM). An aliquot of scraped cells was cytospun on slides $(60 \mathrm{~g}, 7 \mathrm{~min}$, Cytospin Shandon, France) to check the cell type of the samples under light microscopy. The remaining cells were centrifuged $(600 \mathrm{~g}$, 2 min, $4^{\circ} \mathrm{C}$ ) and the pellet was placed in Trizol ${ }^{\mathrm{TM}}$ reagent (GIBCO-BRL, Les Ulis, France) for further RNA extraction.

Each sample was assessed for cell type by taking into account the presence of necrotic cells, squamous, inflammatory (polymorphonuclear cells) and respiratory epithelial cells (Table 1). Samples containing necrotic cells, squamous cells or no respiratory epithelial cells were eliminated (i.e. classes 1,2 , or $3)$.

\section{RT-PCR Analysis}

RNA isolation and cDNA synthesis. Total RNA was isolated using Trizol ${ }^{\mathrm{TM}}$ reagent (GIBCO-BRL) by acid guanidine thiocyanate-phenol-chloroform and precipitated by isopropanol at $-20^{\circ} \mathrm{C}$. RNA $(2 \mu \mathrm{g})$ was placed in a final volume of 20 $\mu \mathrm{L}$ containing 100 units of MMLV Superscript II reverse transcriptase (GIBCO-BRL), $500 \mu \mathrm{M}$ dNTP, $10 \mathrm{mM}$ DTT, and $200 \mathrm{ng}$ of random hexanucleotide primers (Pharmacia Biotech, Saint Quentin en Yvelines, France). cDNA was then diluted 5 -fold in sterile water.

PCR amplification. The specificity of the primers used (Table 2) has been previously reported by our laboratory (17). Amplification of $\beta 2$ microglobulin gene was used as an internal control.

cDNA $(5 \mu \mathrm{L})$ was added to a $25 \mu \mathrm{L}$ final volume containing $2 \mathrm{U}$ of Taq DNA polymerase (Boehringer Mannheim, Meylan, France), $500 \mu \mathrm{M}$ dNTP, variable $\mathrm{MgCl}_{2}$ concentration (Table 2), 20 pmoles of each forward and reverse primer, 10 pmoles of $\beta 2$ microglobulin forward and reverse primers and $1 \mu \mathrm{Ci}$ of $\left[\alpha \mathrm{P}^{32}\right] \mathrm{dCTP}$ (Amersham, Les Ulis, France). The samples were amplified for the adequate number of cycles (30 for all genes except MRP5 and 32 for MRP5) corresponding to the expo-

Table 1. Criteria for the cell type class of nasal samples

\begin{tabular}{lc}
\hline \multicolumn{1}{c}{ Cell type } & Class \\
\hline Necrotic cells or absence of respiratory cells & 1 \\
Necrotic cells & 2 \\
Absence of cells & 3 \\
Squamous cells or rare bare nuclei & \\
Presence of inflammatory (polymorphonuclear) cells & 4 \\
Epithelial cells associated with $>40 \%$ polymorphonuclear cells & 5 \\
Epithelial cells associated with $20-40 \%$ polymorphonuclear cells & 5 \\
Epithelial cells associated with $<20 \%$ polymorphonuclear cells & 6 \\
Absence of inflammatory cells & \\
Ciliated cells $<50 \%$ & 7 \\
Ciliated cells $>50 \%$ & 8 \\
\hline
\end{tabular}


Table 2. Sequences of the forward and reverse primers used for PCR amplifications

\begin{tabular}{|c|c|c|c|}
\hline Genes & Primer sequences $\left(5^{\prime}-3^{\prime}\right)$ & $\mathrm{MgCl}_{2}(\mathrm{mM})$ & $\begin{array}{l}\text { Fragment } \\
\text { length (bp) }\end{array}$ \\
\hline \multirow[t]{2}{*}{ MRP1 } & GGACCTGGACTTCGTTCTCA & 1.5 & 292 \\
\hline & CGTCCAGACTTCATCCG & & \\
\hline \multirow[t]{2}{*}{ MRP2 } & CTGCCTCTTCAGAATCTTAG & 1.8 & 241 \\
\hline & ATAACCCAAGTTGCAGGCT & & \\
\hline \multirow[t]{2}{*}{ MRP3 } & CTCAATGTGGCAGACATCGG & 1.8 & 178 \\
\hline & GGGAGCTCACAAACGTGTGC & & \\
\hline \multirow[t]{2}{*}{ MRP4 } & CCATTGAAGATCTTCCTGG & 2.5 & 240 \\
\hline & GGTGTTCAATCTGTGTGCA & & \\
\hline \multirow[t]{2}{*}{ MRP5 } & GGGATAACTTCTCTCAGTGGG & 2.5 & 383 \\
\hline & GGAATGGCAATGCTCTAAAG & & \\
\hline \multirow{2}{*}{ MDR1 } & GGTGCTGGTTGCTGCTTACA & 1.5 & 291 \\
\hline & TGGCCAAATCACAAGGGT & & \\
\hline \multirow{2}{*}{$\begin{array}{l}\beta 2 \text { micro- } \\
\text { globulin }\end{array}$} & ACCCCCACTGAAAAAGATGA & 1.8 (MRP1-4) & 114 \\
\hline & ATCTTCAAACCTCCATGATG & 2.5 (MRP5) & \\
\hline
\end{tabular}

nential range of amplification reaction and consisting of $1 \mathrm{~min}$ of denaturation at $94^{\circ} \mathrm{C}, 1 \mathrm{~min}$ of annealing at $55^{\circ} \mathrm{C}$ and $1 \mathrm{~min}$ $30 \mathrm{~s}$ of elongation at $72^{\circ} \mathrm{C}$. The positive control used for $M R P 1$ and $M D R 1$ genes was the KB8.5 cell line. The positive controls for $M R P 2,-3,-4$, and -5 genes were human liver for $M R P 2$ and -3 genes, human lung for MRP4 gene and human skeletal muscle for MRP5 gene. Negative controls were included for each amplification (water instead of RNA for reverse transcription and water instead of cDNA for PCR).

Semiquantitative analysis of PCR products. Amplification of the $\beta 2$ microglobulin gene was performed for each sample to account for variability in mRNA extraction, mRNA quantitation and cDNA synthesis. Amplification products were submitted to electrophoresis on $8 \%$ polyacrylamide gels at $750 \mathrm{~V}$ for $3.5 \mathrm{~h}$. After exposure of gels to X OMAT films (Eastman Kodak), autoradiographs were scanned using a Bio-Rad densitometer (Bio-Rad, Ivry sur Seine, France). Each gene mRNA content was expressed as the ratio of the densitometric value of each gene amplification product to that of $\beta 2$ microglobulin amplification product.

\section{Functional Assay for Chloride Conductive Pathways}

Transmembrane chloride conductive pathways were measured in nasal ciliated cells either under basal conditions or after addition of cAMP agonists using a halide-sensitive SPQ fluorescent dye assay, as previously reported (6). Briefly, this method measures the rate of chloride transport as the change in fluorescence of intracellular SPQ in response to exchange of extracellular chloride with nitrate $\left(\mathrm{NO}_{3}{ }^{-}\right)$, an anion that passes through CFTR, but does not quench indicator fluorescence unlike chloride. cAMP agonists consisting of $25 \mu \mathrm{M}$ forskolin, $100 \mu \mathrm{M}$ isobutylmethylxanthine and $500 \mu \mathrm{M}$ 8-(4-chlorophenylthio)-adenosine $3^{\prime}: 5^{\prime}$-cyclic monophosphate were added to activate CFTR resulting in chloride efflux, $\mathrm{NO}_{3}{ }^{-}$influx and increased fluorescence. To enhance the sensitivity of the assay, chloride was replaced by iodide $\left(\mathrm{I}^{-}\right)$, as CFTR is permeable to $\mathrm{I}^{-}$and SPQ fluorescence is more strongly quenched by $\mathrm{I}^{-}$than by chloride.

Basal anion conductance was defined as the maximum fluorescence change $\left(\Delta \mathrm{F}_{\text {basal }} / \Delta \mathrm{t}\right)$ after replacing $\mathrm{I}^{-}$with $\mathrm{NO}_{3}{ }^{-}$.
The cell was considered to have a basal chloride conductive pathway when the maximum fluorescence change $\Delta \mathrm{F}_{\text {basal }} / \Delta \mathrm{t}$ was $>0.1$. cAMP-dependent anion conductance was defined as the greatest fluorescence change $\left(\Delta \mathrm{F}_{\mathrm{cAMP}} / \Delta \mathrm{t}\right)$ after adding cAMP agonists. The cell was considered to have a cAMPstimulated chloride conductive pathway when the maximum fluorescence change after addition of the cAMP agonists $\Delta \mathrm{F}_{\mathrm{cAMP}} / \Delta \mathrm{t}$ was $>0.1$. Results were expressed for each subject studied as the percentage of ciliated cells with basal chloride conductive pathway and the percentage of ciliated cells with cAMP-stimulated chloride conductive pathway. The experimental protocol used is shown in Fig. 1.

\section{Statistics}

Statistical calculations and tests were performed using Stat View 5.0 software (Abacus, CA, U.S.A.). The limit of statistical significance was defined as $p \leq 0.05$.

Means were compared using $t$ tests. Results are expressed as mean \pm SEM. Among CF patients, a subgroup with lower $M R P 1$ levels and another subgroup with lower MRP5 levels were found (Fig. 2) and relationship between MRP1 or MRP5 transcript levels and clinical status (age, FEV1, FVC and Shwachman score) was therefore investigated. The highest MRP1 and MRP5 values in the subgroups with lower levels were 0.145 and 0.077 , respectively. The values 0.15 and 0.08 were therefore chosen as cut-off values to analyze differences in clinical status according to MRP1 or MRP5 levels, respectively.

To investigate whether there was a difference in MRP1 or $M R P 5$ transcript levels $(\leq 0.15$ or $>0.15$ and $\leq 0.08$ or $>0.08$ for $M R P 1$ and $M R P 5$, respectively) and cell type (inflammatory or non inflammatory), the Fisher exact test was used.

Correlation coefficients were calculated for each combination of mRNA levels.

\section{RESULTS}

Cell type of the analyzed nasal samples. Nasal samples containing necrotic cells, squamous cells or no respiratory

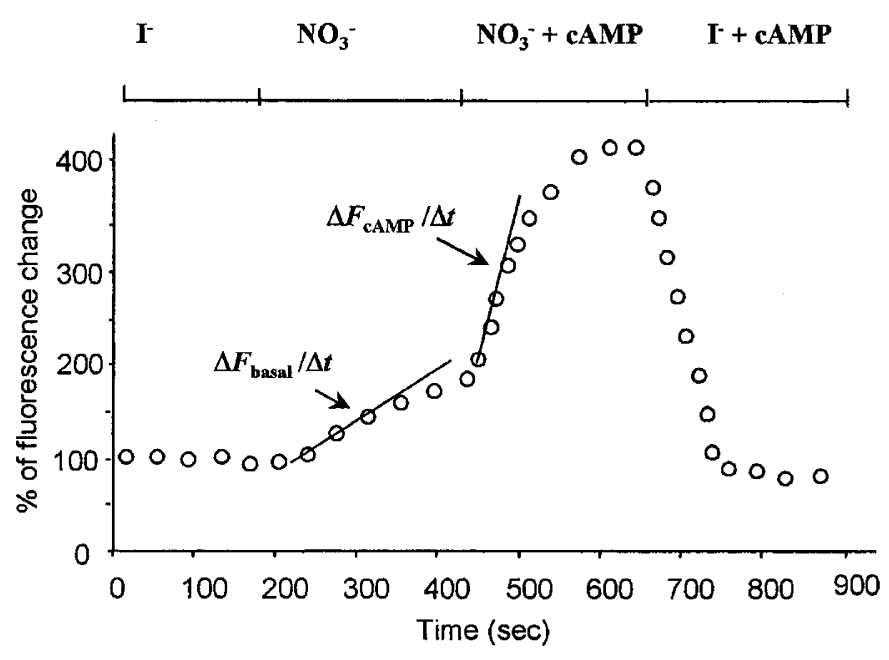

Figure 1. Experimental protocol for SPQ fluorescence assay to measure chloride conductive pathways in nasal ciliated cells. The cells were superfused with $\mathrm{I}^{-}, \mathrm{NO}_{3}{ }^{-}$and then with cAMP agonists. 

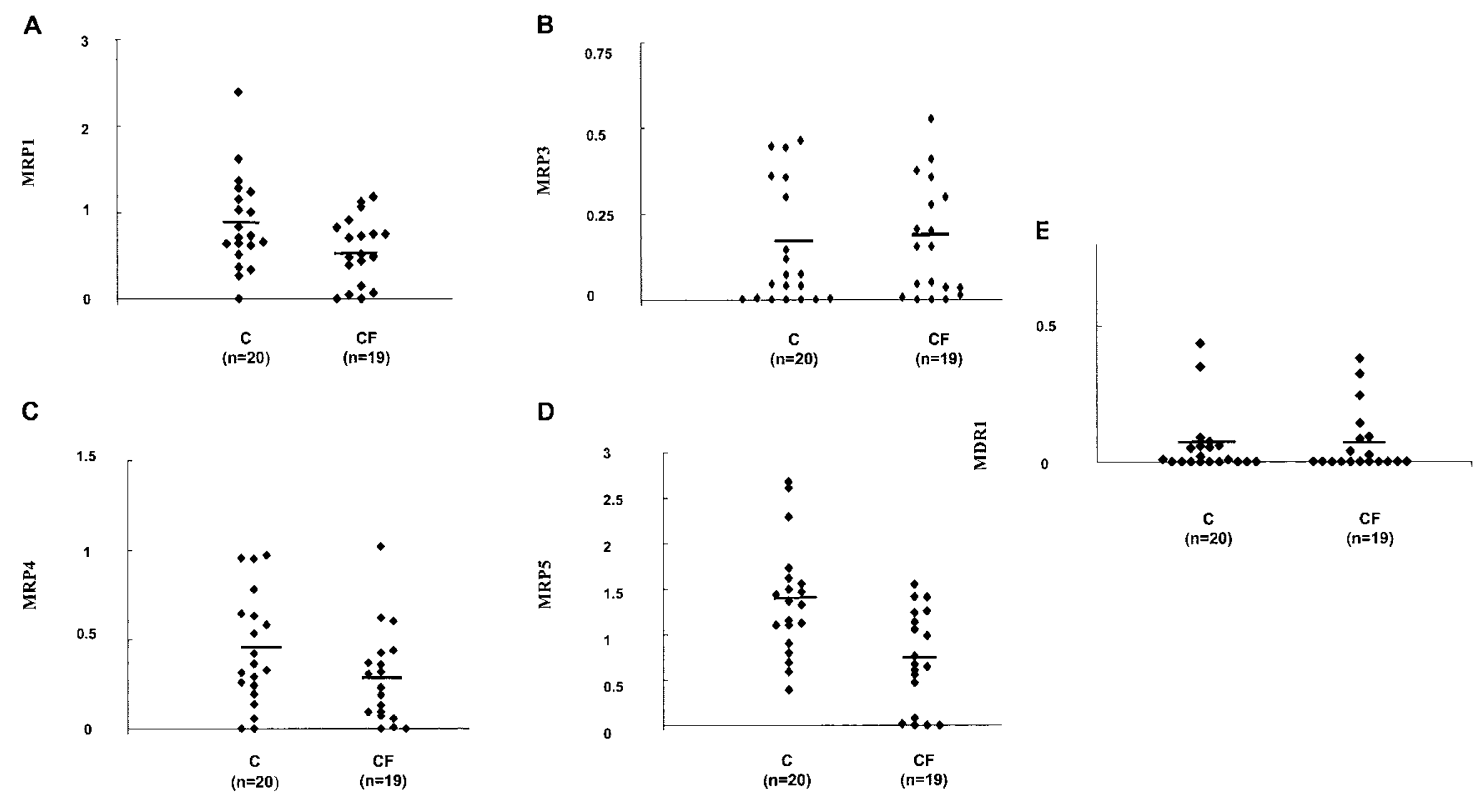

Figure 2. Semiquantitative analysis of $M R P 1(A), M R P 3(B), \operatorname{MRP4}(C), \operatorname{MRP5}(D)$, and MDRI $(E)$ mRNA levels in controls $(\mathrm{C})$ and $\triangle \mathrm{F} 508$ homozygous patients (CF) by densitometric evaluation of each gene PCR product compared with $\beta 2$ microglobulin PCR product. Horizontal line: mean level of expression for each data set.

epithelial cells were eliminated for further analysis (Table 1, classes 1-3). No difference in cell type, as assessed by the cell class, of the remaining samples, was observed between control subjects and $\Delta \mathrm{F} 508$ homozygous patients (Table 3). In both groups, the majority of the samples $(90 \%)$ contained epithelial cells (i.e. ciliated, goblet and basal cells) with no inflammatory cells and were classified 7 or 8 depending on the proportion of ciliated cells.

MRPs and MDR1 transcript levels. Individual results are presented in Table 3. Variable MRP1 transcript levels were observed in control subjects $(0.87 \pm 0.12)$ and $\Delta$ F508 homozygous patients $(0.56 \pm 0.09)$ with significantly lower levels in CF patients $(p<0.05)$ (Fig. $2 A)$. A subgroup of CF patients ( $\mathrm{n}=5$, about $25 \%$ ) with undetectable or very low transcript levels $(\leq 0.15)$ could be distinguished. No difference in cell type was observed between samples from CF patients with MRP1 mRNA levels lower or higher than 0.15 as percentages of samples without inflammatory cells (i.e. classes 7-8) were similar ( $80 \%$ versus $92 \%$, respectively; Fisher exact $\mathrm{p}$ value $=$ $0.5)$.

We found no detectable $M R P 2$ transcripts in any of the nasal samples from all subjects analyzed.

MRP3 transcript levels were similar in controls $(0.15 \pm$ $0.04)$ and CF patients $(0.16 \pm 0.04)$ with undetectable or low $M R P 3$ transcript levels in both groups (Fig. 2B).

Variable MRP4 transcript levels, including low or undetectable mRNA levels, were observed in controls $(0.43 \pm 0.07)$ and $C F$ patients $(0.28 \pm 0.06)$ (Fig. $2 C)$ with no statistical difference between the two groups.

Analysis of MRP5 mRNA showed variable levels among controls $(1.37 \pm 0.14)$ and CF patients $(0.73 \pm 0.12)$ (Fig. $2 D)$. However, MRP5 transcripts $(>0.08)$ were observed in all controls, but were undetectable or very low $(\leq 0.08)$ in about $25 \%$ of CF patients $(\mathrm{n}=5)$ and this difference between CF patients and controls was statistically significant $(p<0.01)$. Cell type was similar in samples from CF patients with MRP5 mRNA levels lower or higher than 0.08 (percentages of samples without inflammatory cells: $100 \%$ versus $85 \%$, respectively; Fisher exact $\mathrm{p}$ value $>0.9$ ). Three patients had low mRNA levels for both MRP1 and MRP5 genes (Table 3).

$M D R 1$ gene encodes for Pgp which is an $\mathrm{ABC}$ transporter involved in efflux of various compounds and belonging to another subfamily (B) than subfamily $\mathrm{C}$ which includes CFTR and MRPs. CFTR and MDR1 genes have been shown to exhibit complementary patterns of epithelial expression, suggesting analogous roles in epithelial cells (18). Therefore, in addition to MRPs, we also analyzed MDR1 gene expression in CF patients. Similar low MDR1 levels were detected in controls $(0.06 \pm 0.03)$ and CF patients $(0.07 \pm 0.03)$ with undetectable transcripts in about one half of subjects in each group (Fig. 2E).

Correlation analysis of gene transcript levels. Correlation coefficients $(r)$ for the correlation of MRPS and MDR1 mRNA levels were calculated taking into account all subjects $(n=39)$ (Table 4). Among the various possible combinations of mRNA data sets, MRP1 and MRP5 transcript levels demonstrated the highest correlation $(r=0.71, p<0.0001)$ (Fig. 3).

Relation with clinical status. As an overlap in MRP1 and MRP5 transcript levels was found between some CF patients and some controls, we investigated whether CF patients exhibiting lower MRP1 $(\leq 0.15, \mathrm{n}=5)$ or lower MRP5 transcript levels $(\leq 0.08, n=5)$ had a different clinical status on the basis of age, FEV1, FVC and Shwachman score (Table 5). No association was found between MRP1 or MRP5 transcript levels and age, FEV1 or FVC (Table 6). However, patients with lower MRPI transcript levels had significantly lower Shwachman scores, although in this subgroup one patient had a maximal score of 100 . No such relation was observed for MRP5 gene. 
Table 3. MRPS and MDR1 transcript levels in healthy controls $(C, n=20)$ and $\Delta F 508$ homozygous patients $(C F, n=19)$

\begin{tabular}{rlclllll}
\hline \multicolumn{2}{c}{ Subject } & Cell class & MRP1 & MRP3 & MRP4 & MRP5 & MDR1 \\
\hline 1 & C & 8 & 0.708 & 0.443 & 0.535 & 1.367 & 0.436 \\
2 & C & 8 & 0.730 & 0.447 & 0.632 & 1.441 & 0.349 \\
3 & C & 8 & 0.386 & 0 & 0 & 0.589 & 0 \\
4 & C & 6 & 1.149 & 0.360 & 0.242 & 1.158 & 0.075 \\
5 & C & 7 & 1.366 & 0 & 0.644 & 1.730 & 0 \\
6 & C & 8 & 0.658 & 0.005 & 0.363 & 0.694 & 0 \\
7 & C & 8 & 1.280 & 0 & 0.056 & 2.291 & 0 \\
8 & C & 8 & 0.644 & 0.001 & 0.138 & 1.103 & 0.007 \\
9 & C & 8 & 0.639 & 0.046 & 0 & 0.799 & 0.009 \\
10 & C & 8 & 1.237 & 0.356 & 0.581 & 1.325 & 0 \\
11 & C & 8 & 0.834 & 0.041 & 0.781 & 1.502 & 0 \\
12 & C & 8 & 2.391 & 0.298 & 0.971 & 2.613 & 0.051 \\
13 & C & 8 & 1.617 & 0.146 & 0.423 & 2.679 & 0 \\
14 & C & 8 & 0.002 & 0.075 & 0.313 & 1.103 & 0 \\
15 & C & 8 & 1.001 & 0 & 0.329 & 1.467 & 0 \\
16 & C & 8 & 1.030 & 0.073 & 0.258 & 1.124 & 0.020 \\
17 & C & 8 & 0.266 & 0.004 & 0.194 & 0.392 & 0.089 \\
18 & C & 8 & 0.335 & 0.119 & 0.954 & 1.622 & 0.058 \\
19 & C & 8 & 0.619 & 0.463 & 0.950 & 1.556 & 0.059 \\
20 & C & 6 & 0.509 & 0.041 & 0.290 & 0.901 & 0.054 \\
21 & CF & 8 & 0.145 & 0 & 0 & 0 & 0 \\
22 & CF & 7 & 0.001 & 0 & 0.091 & 0 & 0.025 \\
23 & CF & 8 & 0 & 0.375 & 0.622 & 1.242 & 0.091 \\
24 & CF & 8 & 0.438 & 0.201 & 0.426 & 0.608 & 0.083 \\
25 & CF & 8 & 0.749 & 0.298 & 0.319 & 0.643 & 0 \\
26 & CF & 4 & 0.066 & 0.154 & 0.073 & 0.470 & 0 \\
27 & CF & nd & 0.707 & 0.155 & 0.057 & 0.762 & 0.039 \\
28 & CF & 7 & 0.724 & 0.206 & 0.188 & 1.134 & 0 \\
29 & CF & 7 & 0.516 & 0 & 0.008 & 0.077 & 0 \\
30 & CF & 8 & 0.909 & 0.014 & 0.231 & 1.256 & 0 \\
31 & CF & 8 & 0.822 & 0.045 & 0.603 & 1.414 & 0 \\
32 & CF & 7 & 0.391 & 0.035 & 0.368 & 0.670 & 0.322 \\
33 & CF & 8 & 1.119 & 0.409 & 0.131 & 1.411 & 0.243 \\
34 & CF & 8 & 0.481 & 0.007 & 0.307 & 0.558 & 0 \\
35 & CF & 8 & 1.064 & 0.034 & 0.437 & 0.001 & 0 \\
36 & CF & 6 & 0.752 & 0.051 & 0 & 0.989 & 0 \\
37 & CF & 8 & 0.044 & 0.277 & 0.094 & 0.017 & 0 \\
38 & CF & 8 & 0.485 & 0.526 & 0.359 & 1.056 & 0.142 \\
39 & CF & 8 & 1.177 & 0.356 & 1.021 & 1.554 & 0.380 \\
\hline & & & & & & & \\
\hline
\end{tabular}

Table 4. Correlation coefficients ( $r$ ) for the correlation of transcript levels in controls and $\Delta F 508$ homozygous patients $(n=39)$

\begin{tabular}{cclll}
\hline & MRP1 & MRP4 & MRP5 & MDR1 \\
\hline MRP3 & & & & \\
$r$ & 0.14 & 0.42 & 0.28 & 0.55 \\
$p$ & 0.39 & 0.008 & 0.09 & 0.0003 \\
MRP1 & & & & \\
$r$ & 0.37 & 0.71 & 0.03 \\
$p$ & & 0.02 & $<0.0001$ & 0.85 \\
MRP4 & & & & \\
$r$ & & 0.55 & 0.34 \\
$p$ & & 0.0003 & 0.03 \\
MRP5 & & & & \\
$r$ & & & 0.15 \\
$p$ & & & & 0.36 \\
\hline
\end{tabular}

Relation with basal and cAMP-dependent chloride conductive pathways. Given that the cAMP-dependent chloride channel function of CFTR varies between $\triangle$ F508 homozygous patients and that this variation is related to the severity of $\mathrm{CF}$ (6), we investigated whether MRP1 or MRP5 gene expression could be related to CFTR function. We measured cAMP-

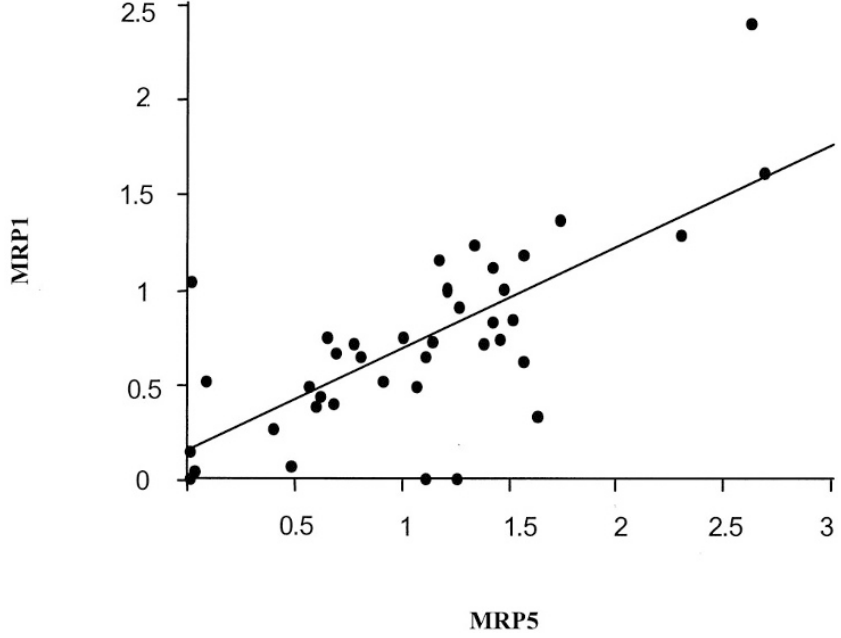

Figure 3. Correlation between MRPI and MRP5 transcript levels in controls and $\Delta$ F508 homozygous patients $(n=39) . r=0.71, p<0.0001$.

dependent chloride conductive pathway using a halidesensitive SPQ fluorescent dye assay in nasal ciliated cells from $\mathrm{CF}$ patients. We also measured chloride conductive pathway under basal conditions, i.e. before addition of cAMP agonists. As we previously reported (6), the percentage of ciliated cells exhibiting basal chloride conductance varies among healthy controls as it is the case for cAMP-dependent chloride conductance. The lowest percentages were $63 \%$ and $50 \%$ for basal and cAMP-dependent chloride conductances, respectively (6). These values were therefore chosen as cut-off values to analyze conductances in $\mathrm{CF}$ patients (see Table 5 for individual results).

As expected, there was a significant difference in the percentage of ciliated cells exhibiting a cAMP-dependent chloride conductive pathway between controls and CF patients (83 \pm $5 \%$ versus $45 \pm 7 \%, p<0.01)$. There was also a significant difference in the percentage of ciliated cells exhibiting a basal chloride conductive pathway between controls and $\mathrm{CF}$ patients (98 $\pm 2 \%$ versus $68 \pm 7 \%, p<0.01$ ).

When considering cAMP-dependent chloride conductive pathway, no difference in MRP1 or MRP5 transcript levels was observed between CF patients with less than or more than $50 \%$ cells showing cAMP-dependent chloride conductive pathway. However, when considering basal chloride conductive pathway, significantly lower MRPI transcript levels were found for $\mathrm{CF}$ patients with less than $63 \%$ cells exhibiting basal chloride conductive pathway ( $p<0.01$ ) (Fig. 4). Although lower MRP5 transcript levels were also found for CF patients with less than $63 \%$ cells with basal chloride conductive pathway $(0.49 \pm 0.19$ versus $0.84 \pm 0.15 \%$ ), this difference was not significant.

\section{DISCUSSION}

The main findings of the present study are: $i$ ) the lower MRP1 and MRP5 transcript levels in $\triangle \mathrm{F} 508$ homozygous patients compared with control subjects and $i i$ ) the associations of MRP1 transcript levels with both clinical status and presence of a cAMP-independent chloride conductive pathway in $\mathrm{CF}$ patients. These results suggest a potential interrelation between 
Table 5. Clinical status (according to age, FEVI, FVC, and Shwachman score) and chloride conductive pathways in CF patients

\begin{tabular}{|c|c|c|c|c|c|c|c|c|c|c|c|c|c|c|}
\hline \multicolumn{2}{|c|}{ Patient } & \multirow{2}{*}{$\frac{S^{*} *}{M}$} & \multirow{2}{*}{$\begin{array}{c}\text { Age } \\
16\end{array}$} & \multirow{2}{*}{$\frac{\text { MRP1 }}{0.145}$} & \multirow{2}{*}{$\begin{array}{c}\text { MRP3 } \\
0\end{array}$} & \multirow{2}{*}{$\begin{array}{c}\text { MRP4 } \\
0\end{array}$} & \multirow{2}{*}{$\frac{\text { MRP5 }}{0}$} & \multirow{2}{*}{$\frac{\text { MDR1 }}{0}$} & \multirow{2}{*}{$\frac{\text { FEV1 }}{74}$} & \multirow{2}{*}{$\frac{\text { FVC }}{61}$} & \multirow{2}{*}{$\begin{array}{c}\text { Shwachman } \\
\text { score }\end{array}$} & \multirow{2}{*}{$\begin{array}{c}\text { Number of } \\
\text { cells tested }\end{array}$} & \multirow{2}{*}{$\begin{array}{c}\begin{array}{c}\% \text { cells with } \\
\Delta \mathrm{F}_{\text {basal }} / \Delta \mathrm{t}>0.1^{* *}\end{array} \\
0\end{array}$} & \multirow{2}{*}{$\begin{array}{c}\text { \% cells with } \\
\Delta \mathrm{F}_{\mathrm{cAMP}} / \Delta \mathrm{t}>0.1^{* *} \\
0\end{array}$} \\
\hline 21 & $\mathrm{CF}$ & & & & & & & & & & & & & \\
\hline 22 & CF & $\mathrm{M}$ & 8 & 0.001 & 0 & 0.091 & 0 & 0.025 & 120 & 123 & 100 & 7 & 0 & 100 \\
\hline 24 & $\mathrm{CF}$ & M & 7 & 0.438 & 0.201 & 0.426 & 0.608 & 0.083 & 98 & 62 & 90 & 13 & 39 & 31 \\
\hline 25 & $\mathrm{CF}$ & $\mathrm{F}$ & 11 & 0.749 & 0.298 & 0.319 & 0.643 & 0 & 97 & 89 & 80 & 28 & 46 & 46 \\
\hline 26 & $\mathrm{CF}$ & M & 16 & 0.066 & 0.154 & 0.073 & 0.470 & 0 & 85 & 90 & 80 & 15 & 60 & 60 \\
\hline 29 & $\mathrm{CF}$ & F & 8 & 0.516 & 0 & 0.008 & 0.077 & 0 & 90 & 92 & 80 & 13 & 69 & 39 \\
\hline 30 & $\mathrm{CF}$ & M & 30 & 0.909 & 0.014 & 0.231 & 1.256 & 0 & 75 & 71 & 90 & 17 & 71 & 82 \\
\hline 31 & $\mathrm{CF}$ & $\mathrm{F}$ & 12 & 0.822 & 0.045 & 0.603 & 1.414 & 0 & 99 & 91 & 90 & 8 & 75 & 50 \\
\hline 32 & $\mathrm{CF}$ & $\mathrm{F}$ & 11 & 0.391 & 0.035 & 0.368 & 0.670 & 0.322 & 59 & 73 & 70 & 11 & 82 & 18 \\
\hline 33 & $\mathrm{CF}$ & M & 9 & 1.119 & 0.409 & 0.131 & 1.411 & 0.243 & 107 & 110 & 100 & 17 & 88 & 29 \\
\hline 34 & $\mathrm{CF}$ & M & 5 & 0.481 & 0.007 & 0.307 & 0.558 & 0 & 100 & 100 & 100 & 16 & 94 & 100 \\
\hline 39 & $\mathrm{CF}$ & $\mathrm{F}$ & 10 & 1.177 & 0.356 & 1.021 & 1.554 & 0.380 & 100 & 100 & 100 & 18 & 100 & 50 \\
\hline
\end{tabular}

* M, male; F, female.

** Results concerning basal and cAMP dependent chloride conductive pathways are expressed as percentages of nasal ciliated cells with maximal fluorescence change $\Delta \mathrm{F}_{\text {basal }} / \Delta \mathrm{t}>0.1$ and $\Delta \mathrm{F}_{\mathrm{cAMP}} / \Delta \mathrm{t}>0.1$, respectively.

Table 6. Age, FEV1, FVC, and Shwachman score according to MRP1 (A) and MRP5 transcript levels (B) in CF patients ( $\mathrm{n}=19)$. Results are expressed as mean \pm SEM.

\begin{tabular}{lccc}
\hline \multicolumn{4}{c}{ A. } \\
& $\begin{array}{c}\text { MRP1 } \leq 0.15 \\
(n=5)\end{array}$ & $\begin{array}{c}\text { MRP1 }>0.15 \\
(n=14)\end{array}$ & $p$ \\
\hline Age & $14 \pm 2$ & $12 \pm 2$ & 0.4 \\
FEV1 & $87 \pm 8$ & $89 \pm 4$ & 0.8 \\
FVC & $87 \pm 11$ & $89 \pm 5$ & 0.8 \\
Shwachman score & $74 \pm 7$ & $88 \pm 3$ & 0.05 \\
\hline \multicolumn{2}{c}{ B. } & \\
\hline & MRP5 $\leq 0.08$ & MRP5 $>0.08$ & \\
& $(n=5)$ & $(n=14)$ & $p$ \\
\hline Age & $14 \pm 2$ & $12 \pm 2$ & 0.6 \\
FEV1 & $88 \pm 8$ & $89 \pm 4$ & 0.8 \\
FVC & $84 \pm 11$ & $90 \pm 5$ & 0.5 \\
Shwachman score & $76 \pm 7$ & $87 \pm 3$ & 0.1 \\
\hline
\end{tabular}

MRPs and CFTR and that MRPs, especially MRP1, might play an important role in the pathophysiology of $\mathrm{CF}$.

The lower expression of MRP 1 and MRP 5 genes observed in $\mathrm{CF}$ patients compared with controls, which was not due to differences in cell type of the analyzed nasal samples, raises the question of the mechanisms of this down-regulation. Regulation of expression of MRPs genes is still poorly known. MRPI expression has been shown to be modulated by drugs and toxins (19), oxidative stress (20), Nmyc (21) and p53 (22-23) and down regulated by elevated glutathione levels (20) and wild-type p53 (23). CF lung disease, which is the major cause of death, is characterized by chronic inflammation and severe oxidative stress in the airways. Oxidative stress may therefore be involved in MRP1 regulation in CF patients. Even fewer data are available concerning the mechanisms of MRP5 gene regulation. In contrast with $M R P 1, M R P 5$ does not appear to be regulated by pro-oxidants (24).

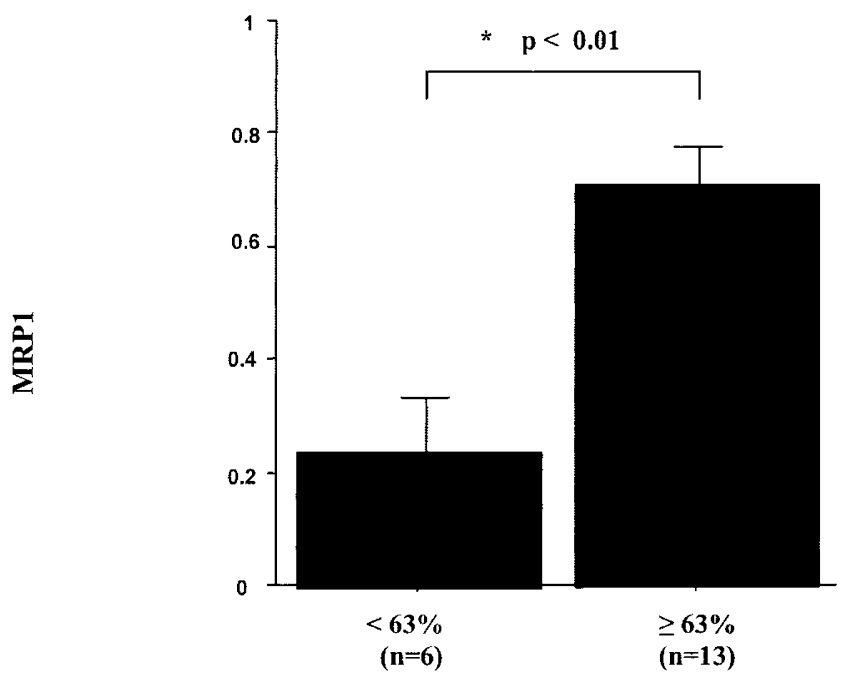

Figure 4. MRP1 transcript levels according to the percentage of nasal ciliated cells exhibiting a $\Delta \mathrm{F}_{\text {basal }} / \Delta \mathrm{t}$ fluorescence change $>0.1$. The $63 \%$ value was the lowest percentage observed in controls as previously reported (6) and was therefore chosen as cut-off value. Significantly lower MRP1 transcript levels were found for $\mathrm{CF}$ patients with less than $63 \%$ cells exhibiting basal chloride conductance: $0.23 \pm 0.12$ vs $0.7 \pm 0.09 \%, p<0.01$.

The highest correlation among MRPs genes between MRPI and MRP5 transcript levels for control subjects and CF patients (Fig. 3) suggests that these two genes may be co-ordinately regulated under physiologic conditions and in $\mathrm{CF}$. Interestingly, in another non-CF pathologic setting, namely lung cancer, no such strong correlation was found between MRPl and MRP5 mRNA levels, while the highest correlation was observed between MRP1 and MRP3 mRNA levels (25). The mechanisms of MRPs gene regulation and consequently their co-regulation may therefore be different in different diseases.

Defective cAMP-dependent chloride transport in the apical membrane of secretory epithelia has been considered to be the 
underlying source of CF pathophysiology. However, there is growing evidence that $\mathrm{CF}$ pathogenesis might be not solely related to the defective chloride channel function, but also to other nonion channel functions of CFTR and to "modifier" genes (26-27). An interesting finding of the present study is the association between MRP1 transcript levels and clinical course of CF disease, as low MRP1 levels were associated with more severe disease, as assessed by the Shwachman score, than high MRP1 levels. Although this result may be incidental and needs further investigation on a larger series of patients, it suggests that MRP1 could be involved in CF pathophysiology and could constitute a "modifier" gene in CF. Although MRP1 is localized to the basolateral membrane of epithelial cells, especially respiratory ciliated cells (10), as opposed to CFTR which is on the apical membrane, CFTR and MRP1 may have similar functions, such as efflux of organic anions (14) or glutathione (15). The function of MRP1 possibly involved in the clinical course of CF might be related to either a nonchloride channel function and/or the chloride channel function of CFTR. MRP1 is thought to be involved in various physiologic or pathologic processes, some of which may be potentially relevant in CF pathophysiology, such as inflammation and antioxidant defense.

Among MRPs, MRP1 has the highest affinity for leukotriene C4 (28), a potent mediator of the inflammatory response causing edema and increased vascular permeability. A decreased inflammatory response was observed in a MRP1deficient mouse model, consistent with a role of MRP1 in mediating leukotriene $\mathrm{C} 4$ export (29). As bronchial cells are known to produce various types of leukotrienes, especially leukotriene C4 (30), one of the functions of MRP1 in respiratory cells could be efflux of endogenously synthesized leukotriene $\mathrm{C} 4$. The absence of an effective inflammatory response via MRP1 could therefore be involved in the more severe clinical course of $\mathrm{CF}$ in patients with low MRPI transcript levels.

Oxidative stress is increased in CF patients due to chronic inflammation and evidence for inadequate antioxidant defense has been reported (31). In particular, glutathione (GSH), which is a major antioxidant in the lung, is decreased in the apical fluid from CF airway epithelial cells (32). As MRP1 can transport GSH out of cells into the interstitial compartment, MRP1 might play a protective role against toxic compounds generated by oxidative stress (11). Oxidative stress has been shown to increase paracellular permeability (33). GSH might therefore reach the airway lining fluid from the interstitial compartment via the paracellular route during oxidative stress. CF patients with lower MRPI levels might have lower GSH in airway fluid via lower efflux of GSH by MRP1 and subsequently they might have a more severe disease via a lack of adequate protective role in the lung against oxidants due to defective MRP1.

The striking relation between MRP1 transcript levels and the existence of a basal chloride conductive pathway in CF patients (Fig. 4) strongly suggests that MRP1 may have a chloride channel-related function. Therefore, MRP1 could be involved in the better clinical status of CF patients with high MRPI levels via this chloride channel-related function in addition to the possible functions discussed above.

A chloride channel-related function has been previously reported in human cell lines overexpressing MRP1 (34-35). Whether MRP1 might act as a chloride channel by itself or regulate, directly or indirectly, a chloride channel remains to be determined. Given the basolateral localization of MRP1 and its possible implication in CF pathophysiology, we hypothesize that MRP1 rather indirectly regulates a chloride channel localized to the apical membrane as CFTR. Our results suggest that the channel regulated by MRP1 would be different from CFTR, as no association was demonstrated between MRP1 mRNA levels and the existence of cAMP-dependent chloride conductance characteristic of CFTR.

Although we found a correlation between MRP1 and MRP5 transcript levels, we found no association of MRP5 with either clinical status or chloride conductive pathway. A possible explanation is that the group of patients with low MRPI mRNA levels was not the same as the group with low MRP5 levels.

As no effective treatment for $\mathrm{CF}$ is yet available, many different treatment strategies are being developed in addition to transfection of normal CFTR gene, especially activation of defective CFTR or non-CFTR chloride channels by pharmacological agents. Although there is need to further evaluate MRPs in CF at the protein level, our results suggest that MRP1 could constitute a new target for pharmacotherapy for CF. Based on the findings that (i) low MRP1 gene expression was associated with more severe disease and (ii) levels were positively associated with the existence of a cAMP-independent chloride conductive pathway, a new therapeutic approach might consist of inducing MRP1 in CF patients. Such pharmacological modulation of MRP1 in CF patients, associated with restored chloride conductance, has been very recently reported in an abstract (36).

Acknowledgments. The authors thank C. Durrant and J. Lehmann-Che for skillful assistance and J.H. Calvet for helpful discussion.

\section{REFERENCES}

1. Stutts MJ, Rossier BC, Boucher RC 1997 Cystic fibrosis transmembrane conductance regulator inverts protein kinase A-mediated regulation of epithelial sodium channel single channel kinetics. J Biol Chem 272:14307-14040

2. Gabriel SE, Clarke LL, Boucher RC, Stutts MJ 1993 CFTR and outwardly rectifying chloride channels are distinct proteins with a regulatory relationship. Nature 363:263268

3. Schreiber R, Nitschke R, Greger R, Kunzelmann K 1999 The cystic fibrosis transmembrane conductance regulator activates aquaporin 3 in airway epithelial cells. J Biol Chem 274:11811-11816

4. Bradbury NA, Jilling T, Berta G, Sorscher EJ, Bridges RJ, Kirk KL 1992 Regulation of plasma membrane recycling by CFTR. Science 256:530-532

5. Barasch J, Kiss B, Prince A, Saiman L, Gruenert DC, Al-Awqati Q 1991 Defective acidification of intracellular organelles in cystic fibrosis. Nature 352:70-73

6. Sermet-Gaudelus I, Vallee B, Hurbain I, Torossi T, Marianovski R, Fajac A, Feuillet MN, Bresson JL, Lenoir G, Bernaudin JF, Edelman A 2002 Normal function of the cystic fibrosis conductance regulator protein can be associated with homozygous $\Delta$ F508 mutation. Pediatr Res 52:628-635

7. Cole SP, Bhardwaj G, Gerlach JH, Mackie JE, Grant CE, Almquist KC, Stewart AJ, Kurz EU, Duncan AMV, Deeley GR 1992 Overexpression of a transporter gene in a multidrug-resistant human lung cancer cell line. Science 258:1650-1654

8. Allikmets R, Gerrard B, Hutchinson A, Dean M 1996 Characterization of the human $\mathrm{ABC}$ superfamily: isolation and mapping of 21 new genes using the expressed sequence tags database. Hum Mol Genet 5:1649-1655 
9. Kool M, de Haas M, Scheffer GL, Scheper RJ, van Eijk MJT, Juijn JA, Baas F, Bors P 1997 Analysis of expression of cMOAT (MRP2), MRP3, MRP4 and MRP5, homologues of the multidrug resistance-associated protein gene (MRP1) in human cancer cell lines. Cancer Res 57:3537-3547

10. Brechot JM, Hurbain I, Fajac A, Daty N, Bernaudin JF 1998 Different pattern of MRP localization in ciliated and basal cells from human bronchial epithelium. J Histochem Cytochem 46:513-517

11. Leslie EM, Deeley RG, Cole SPC 2001 Toxicological relevance of the multidrug resistance protein 1, MRP1 (ABCC1) and related transporters. Toxicology 167:3-23

12. Borst P, Evers R, Kool M, Wijnholds J 2000 A family of drug transporters: the multidrug resistance-associated proteins. J Natl Cancer Inst 92:1295-1302

13. Lallemand JY, Stoven V, Annereau JP, Boucher J, Blanquet S, Barthe J, Lenoir G 1997 Induction by antitumoral drugs of proteins that functionally complement CFTR: a novel therapy for cystic fibrosis? Lancet 350:711-712

14. Linsdell P, Hanrahan JW 1998 Adenosine triphosphate-dependent asymmetry of anion permeation in the cystic fibrosis transmembrane conductance regulator chloride channel. J Gen Physiol 111:601-614

15. Linsdell P, Hanrahan JW Glutathione permeability of CFTR 1998 Am J Physio 275:323-326

16. Shwachman H, Kulczycki LL 1958 Long term study of one hundred and five patient with cystic fibrosis. Am J Dis Child 96:6-15

17. Decleves X, Fajac A, Lehmann-Che J, Tardy M, Mercier C, Hurbain I, Laplanche JL, Bernaudin JF, Scherrmann JM 2002 Molecular and functional MDR1-Pgp and MRPs expression in human glioblastoma multiforme cell lines. Int J Cancer 98:173-180

18. Trezise AE, Romano PR, Gill DR, Hyde SC, Sepulveda FV, Buchwald M, Higgin CF 1992 The multidrug resistance and cystic fibrosis genes have complementary patterns of epithelial expression. EMBO J 11:4291-4303

19. Schrenk D, Baus PR, Ermel N, Klein C, Vorderstemann B, Kauffmann HM 2001 Up-regulation of transporters of the MRP family by drugs and toxins. Toxicol Lett 120:51-57

20. Yamane Y, Furuichi M, Song R, Van NT, Mulcahy RT, Ishikawa T, Kuo MT 1998 Expression of multidrug resistance protein/GS-X pump and $\gamma$-glutamylcysteine synthetase genes is regulated by oxidative stress. J Biol Chem 273:31075-31085

21. Haber M, Bordow SB, Gilbert J, Madafiglio J, Kavallaris M, Marshall GM, Mechetner EB, Fruehauf JP, Tee L, Cohn SL, Salwen H, Schmidt ML, Norris MD 1999 Altered expression of the MYCN oncogene modulates MRP gene expression and response to cytotoxic drugs in neuroblastoma cells. Oncogene 18:2777-2782

22. Sullivan GF, Yang JM, Vassil A, Yang J, Bash-Babula J, Hait WN 2000 Regulation of expression of the multidrug resistance protein MRP1 by p53 in human prostate cancer cells. J Clin Invest 105:1261-1267

23. Wang Q, Beck WT 1998 Transcriptional suppression of multidrug resistance-associated protein (MRP) gene expression by wild-type p53. Cancer Res 58:5762-5769
24. Lin-Lee YC, Tatebe S, Savaraj N, Ishikawa T, Kuo MT 2001 Differential sensitivities of the MRP gene family and $\gamma$-glutamylcysteine synthetase to pro-oxidants in human colorectal carcinoma cell lines with different p53 status. Biochem Pharmacol 61:555563

25. Young LC, Campling BG, Voskoglou-Nomikos T, Cole SPC, Deeley RG, Gerlach JH 1999 Expression of multidrug resistance protein-related genes in lung cancer: correlation with drug response. Clin Cancer Res 5:673-680

26. Schwiebert EM, Dale JB, Egan ME, Stutts MJ, Guggino WB 1999 CFTR is a conductance regulator as well as a chloride channel. Physiol Rev 79:S145-S166

27. Bronsveld I, Mekus F, Bijman J, Ballmann M, de Jonge HR, Laabs U, Halley DJ, Ellemunter H, Mastella G, Thomas S, Veeze HJ, Tümmler B 2001 Chloride conductance and genetic background modulate the cystic fibrosis phenotype of $\Delta \mathrm{F} 508$ homozygous twins and siblings. J Clin Invest 108:1705-1715

28. Leier I, Jedlitschky G, Buchholz U, Cole SPC, Deeley RG, Keppler D 1994 The MRP gene encodes an ATP-dependent export pump for leukotriene C4 and structurally related conjugates. J Biol Chem 269:27807-27810

29. Wijnholds J, Evers R, van Leusden MR, Mol CA, Zaman GJ, Mayer U, Beijnen JH, van der Valk M, Krimpenfort P, Borst P 1997 Increased sensitivity to anticancer drugs and decreased inflammatory response in mice lacking the multidrug resistanceassociated protein. Nat Med 3:1275-1279

30. Holtzman MJ 1991 Arachidonic acid metabolism. Implications of biological chemistry for lung function and disease. Am Rev Respir Dis 143:188-203

31. Brown RK, Wyatt H, Price JF, Kelly FJ 1996 Pulmonary dysfunction in cystic fibrosis is associated with oxidative stress. Eur Respir J 9:334-339

32. Gao L, Kim KJ, Yankaskas JR, Forman HJ 1999 Abnormal glutathione transport in cystic fibrosis airway epithelia. Am J Physiol 277 (Lung Cell Mol Physiol 21):L113L118

33. Rao RK, Baker RD, Baker SS, Gupta A, Holycross M 1997 Oxidant-induced disruption of intestinal epithelial barrier function: role of protein tyrosine phosphorylation. Am J Physiol 273 (Gastrointest Liver Physiol 36):G812-G823

34. Jirsch J, Deeley RG, Cole SPC, Stewart AJ, Fedida D 1993 Inwardly rectifying K ${ }^{+}$ channels and volume-regulated anion channels in multidrug resistant small cell lung cancer cells. Cancer Res 53:4156-4160

35. Hainsworth AH, Henderson RM, Hickman ME, Hladky SB, Rowlands T, Twentyman PR, Barrand MA 1996 Hypotonicity-induced anion fluxes in cells expressing the multidrug-resistance-associated protein, MRP. Pflugers Arch 432:234-240

36. Pradal U, Delmarco A, Morganti M, Cippoli M, Mini E, Cazzola G 2002 Azithromycin induces over-expression of the multidrug resistance-associated protein (MRP) and restores chloride conductance in cystic fibrosis. J Cystic Fibrosis 1:S52 (Abstr) 